\title{
Cultura Cultura
}

\section{Robert Darnton, George Washington's False Teeth. An}

Unconventional Guide to the Eighteenth Century, Nova Iorque/Londres, W. W. Norton, 2003, 208 pp.

\section{João Pedro Rosa Ferreira}

\section{(2) OpenEdition \\ Journals}

\section{Edição electrónica}

URL: http://journals.openedition.org/cultura/3608

DOI: $10.4000 /$ cultura.3608

ISSN: 2183-2021

\section{Editora}

Centro de História da Cultura

\section{Edição impressa}

Data de publição: 1 janeiro 2005

Paginação: 371-374

ISSN: 0870-4546

\section{Refêrencia eletrónica}

João Pedro Rosa Ferreira, "Robert Darnton, George Washington's False Teeth. An Unconventional Guide to the Eighteenth Century, Nova lorque/Londres, W. W. Norton, 2003, 208 pp. », Cultura [Online], vol. 21 I 2005, posto online no dia, consultado a 24 setembro 2020. URL : http://journals.openedition.org/ cultura/3608; DOI : https://doi.org/10.4000/cultura.3608

Este documento foi criado de forma automática no dia 24 setembro 2020.

(c) CHAM - Centro de Humanidades / Centre for the Humanities 


\title{
Robert Darnton, George Washington's False Teeth. An Unconventional Guide to the Eighteenth Century, Nova Iorque/Londres, W. W. Norton, 2003, 208 pp.
}

\author{
João Pedro Rosa Ferreira
}

\section{REFERÊNCIA}

Robert Darnton, George Washington's False Teeth. An Unconventional Guide to the Eighteenth Century, Nova Iorque/Londres, W. W. Norton, 208 pp.

1 O título e o pós-título advertem logo à partida o leitor de que está perante um livro portador de alguma dose de provocação. Em português poderíamos traduzi-lo por Os Dentes Postiços de George Washington. Um Guia Não convencional do Século XVIII. ${ }^{1}$ Trata-se de um conjunto de oito ensaios sobre temas de história das ideias e das mentalidades setecentistas, a que o autor tem dedicado em exclusivo a sua já longa carreira de investigador. O objectivo é ao mesmo tempo simples e ambicioso - "abrir linhas de comunicação com o século XVIII e, ao segui-las até às fontes, compreender o século 'como ele realmente foi', em toda a sua estranheza" (p. xv).

$\mathrm{Na}$ esteira do título, pode dizer-se que também Robert Darnton é um historiador pouco convencional, pelo tom irreverente da escrita e pela ironia fina com que "tempera" os seus trabalhos - quanto ao conteúdo, o conjunto da sua obra assenta numa investigação original, sustentada por uma sólida erudição que lhe granjeou prestígio internacional. Nascido em 1939, em Nova Iorque, Darnton estudou na Universidade de Harvard, onde obteve uma Bolsa Rhodes que lhe permitiu fazer o doutoramento em Oxford, em 1964. Regressado aos Estados Unidos, trabalhou como jornalista no New York Times e ensinou 
nas universidades de Harvard, Stanford e Princeton, além de leccionar sucessivos cursos na Europa (Instituto de Altos Estudos, na Holanda; Collège de France; Oxford e Warwick, em Inglaterra). Foi presidente da American Historical Association e da Sociedade Internacional de Estudos do Século XVIII. Actualmente, é titular da cátedra Shelby Collum Davis de História da Europa na Universidade de Princeton.

Herdeiro intelectual da escola dos Annales, Robert Darnton reconhece igualmente no seu trabalho a grande influência da nova história do livro e da leitura, particularmente os trabalhos de Roger Chartier. Como resultado de 25 anos de "imersão" nos arquivos da Société Typographique de Nêuchatel, na Suíça, onde foram impressos muitos dos livros marcantes da época das Luzes, Darnton logrou alcançar uma nova perspectiva sobre as décadas finais do Antigo Regime. O conjunto da sua obra permite-nos acompanhar a circulação das ideias na sociedade francesa a partir do estudo da produção, venda, distribuição e leitura de livros, gazetas, pasquins e folhetos. 0 seu objectivo como historiador é, conforme afirmou numa entrevista, "mostrar não só o que as pessoas liam, mas também como pensavam, como construíam o seu mundo, como lhe davam significado e lhe infundiam emoções". É autor de dezenas de artigos científicos e de mais de uma dúzia de livros, entre os quais Mesmerism and the End of the Enlightenment in France, Cambridge (Massachusetts), Harvard University Press, 1968; The Literary Underground of the Old Regime, Cambridge (Massachusetts), Harvard University Press, 1982, traduzido para francês como Bohème littéraire et révolution. Le monde des livres au XVIIIe siècle, 1983; The Great Cat Massacre and Other Episodes in French Cultural History, Nova Iorque, Basic Books, 1984 (edição brasileira: O Grande Massacre de Gatos e outros episódios da história cultural francesa, Rio de Janeiro, Graal, 1986); Edition et sédition. L'univers de la littérature clandestine au XVIIIe siècle, Paris, Gallimard, 1991; e The Forbidden Best-Sellers of Prerevolutionary France, W. W. Norton, 1995.

O vasto saber acumulado - e partilhado - por Robert Darnton permite-lhe partir para este seu livro mais recente com uma certeza: "tudo o que diz respeito ao século XVIII é estranho" (Introdução, p. ix) e "visite o século XVIII e regressará com a cabeça à roda, porque ele é infinitamente surpreendente, inexaurivelmente interessante $e$ irresistivelmente estranho" (p. x). Para ilustrar esta premissa, começa por contar que, ao tomar posse como primeiro Presidente dos Estados Unidos, em 1789, George Washington tinha um único dente na boca, um bicúspide esquerdo de baixo. Para colmatar a falta de dentes, o "Pai Fundador" da América tinha uma vasta colecção de postiços - de marfim de elefante, de presas de morsa e de hipopótamo, além, claro, de dentes humanos. No entanto, apressa-se a acrescentar Darnton, Washington "não estava sozinho na luta contra as doenças dos dentes. Os seus contemporâneos, provavelmente, preocupavam-se mais com as dores nas gengivas do que com a nova Constituição de 1787" (p. ix).

5 A propósito, ficamos também a saber que a personagem mais famosa da Paris setecentista (além do carrasco oficial) era um arrancador de dentes conhecido como Le Grand Thomas, que exercia o ofício na Pont-Neuf. Nem o próprio Rei-Sol era imune às dores de dentes... e respectivas consequências: os médicos de Luís XIV fracturaram-lhe o maxilar ao tentarem extrair molares podres.

6 Com estes e outros episódios, aparentemente do âmbito da "petite histoire", o autor fornece "um guia para o século XVIII, não para todo ele (isso exigiria um tratado em vários volumes) mas para alguns dos seus cantos mais curiosos e recônditos e também para a sua questão principal, a causa das Luzes" (p. xi). Ao estudar o mundo mental de 
setecentos, Darnton enfrenta um problema: os temas em causa têm, de uma maneira ou de outra, afinidades com questões actuais. E se o primeiro mandamento do historiador é "Não cometerás anacronismo", o perigo do presentismo torna-se insidioso. É que, explica ele, "Não há acesso ao passado sem intermediários" (p. xii) - e os intermediários são os nossos próprios olhos. O dilema é incontornável. A citação é longa mas vale a pena:

"Os historiadores enfrentam este dilema recorrendo a um ethos profissional. Tentam reconstruir o passado 'como ele realmente foi', de acordo com as regras estabelecidas por Ranke, na senda de Tucídides. Mas este compromisso tem um preço, pois o historiador profissional tende a ser esotérico e os historiadores profissionais, com frequência, escrevem uns para os outros, separados do público em geral por um muro de erudição destinado a protegê-los. Este livro tenciona quebrar essa barreira. É escrito para o leitor instruído e pretende dar uma perspectiva histórica a questões actuais, tais como: A adopção do euro veio pôr em causa noções adquiridas sobre a identidade da Europa? A Internet criou uma nova sociedade de informação? A obsessão com a vida privada das figuras públicas pode evidenciar linhas de fractura na cultura política? Ao projectar estas questões contra um pano de fundo do século XVIII, penso ser possível vê-las a uma nova luz, desfrutando, ao mesmo tempo, de uma visão mais fresca do século XVIII.

Isto pode parecer um anacronismo desavergonhado. Espero, no entanto, ser capaz de enfrentar o elemento presentista implícito em cada imagem do passado pelo facto de o reconhecer e de levá-lo em conta à partida... Fazer o passado parecer uma terra estranha demasiado distante pode cortar-lhe o acesso. Em vez de reificar culturas estranhas na esperança de capturar qualquer coisa que imaginamos ser a sua essência, devemos antes interrogá-las. Precisamos aprender a falar as suas línguas, de fazer as perguntas correctas às fontes relevantes e traduzir as respostas para um idioma que possa ser compreendido pelos nossos contemporâneos.

Não vejo um caminho fácil para contornar o duplo perigo do passéisme e do presentismo, excepto andar num vai-vem entre os séculos, à procura de novas perspectivas. Mas o valor da história, tal como eu a entendo, é esse: não dar lições mas proporcionar perspectiva." (pp. xii-xiii)

7 O melhor fica para o fim: o prazer que dá "viajar" na história, sobretudo (de acordo com Darnton) para os que se dirigem ao século XVIII. Apesar de muito do que se julgava certo sobre a época pertencer, afinal, à categoria de mito (por exemplo, que Washington tinha dentes postiços de madeira), a verdade é que os "mitos deram forma às mentalidades" (p. xv).

O primeiro ensaio, intitulado "Em defesa das Luzes: os dentes postiços de George Washington" (pp. 3-24), parte do princípio que o conceito de Luzes foi inflacionado, acabando por ser levado a coincidir praticamente com o de modernidade ou, genericamente, com a civilização Ocidental. Darnton lança-se à tarefa de o deflacionar, estabelecendo-lhe balizas cronológicas e conceptuais. Ao libelo acusatório apresentado contra as Luzes pelo pós-modernismo, o autor responde com uma defesa bastante convincente, concluindo a favor do progresso ("com p pequeno"), tendo em conta os ganhos obtidos pelo prazer sobre a dor nos últimos 200 anos e a simpatia que merecem aqueles que se ergueram em defesa dos direitos humanos contra a desumanidade acima de todos, Voltaire.

9 Em "As notícias em Paris: uma sociedade de informação precoce" (pp. 25-75), o autor contesta a ideia de que a era da informação seja exclusiva da época actual. Defende, pelo contrário, que por volta de 1750 havia um sistema de comunicações em funcionamento, cujo centro de difusão era a Árvore de Cracóvia, nos jardins do PalaisRoyal, em Paris. Ali se juntavam os "nouvelistes de bouche" que divulgavam notícias e 
boatos, em seguida espalhados pelos jardins e cafés da capital francesa e, a partir daí, por todo o país. Além destas notícias orais, as notícias à mão (poemas, cartas, pasquins), os periódicos e panfletos impressos e os livros completavam o circuito de comunicação na França de meados do século XVIII.

10 "A unidade da Europa: cultura e boas maneiras" (pp. 76-88) aborda a identidade do Continente e reflecte sobre a possibilidade de uma integração europeia, desde o mito do rapto de Europa, filha de Agenor de Tiro, passando pelas conquistas de César, Carlos Magno, Napoleão e Hitler, pelo cosmopolitismo kantiano e a Declaração dos Direitos do Homem de 1789 até à adopção do euro como moeda única.

11 "A busca da felicidade: Voltaire e Jefferson" (pp. 89-106) é uma viagem às origens da ideia de felicidade, um marco da cultura americana, que remonta a Platão e Aristóteles e também aos epicuristas e aos estóicos. A leitura do autor de Candide teve uma importância seminal no redactor da Declaração de Independência da América.

Rousseau, o romântico, ou Rousseau, o pai do totalitarismo, é a questão central de "A grande divisão: Rousseau na estrada de Vincennes" (pp. 107-118). Foi no caminho para casa do seu amigo Diderot, em Vincennes, no Verão de 1749, que Rousseau leu num jornal o anúncio ao concurso literário promovido pela Academia de Dijon sobre o tema: "Se o restabelecimento das ciências e das artes contribuiu para a purificação dos costumes". 0 resultado foi o Discurso sobre as Ciências e as Artes, que ganhou o prémio da Academia em 1750 e fez a celebridade do cidadão de Genebra.

o período que se seguiu à independência dos Estados Unidos assistiu a uma autêntica Americomania em França. Nos teatros de vaudeville, na pintura, na música, na moda... não passava um dia em que Le Journal de Paris, o único diário francês da época, não trouxesse "o último grito" do outro lado do Atlântico. Entre os maiores entusiastas contavam-se dois vultos que partilhariam o destino trágico dos girondinos na Revolução que se aproximava. É o tema de "A mania da América: Condorcet e Brissot" (pp. 119-136).

Luzes e especulação - podia ser este o título do ensaio "A busca do lucro: Rousseauismo na Bolsa" (pp. 137-155), que estuda a derrapagem especulativa da Bolsa de Paris em 1785-87, por acção de Étienne Clavière e de Brissot, que faziam negócios pouco transparentes ao mesmo tempo que escreviam panfletos citando, de forma apologética, Rousseau.

O último ensaio, "Os esqueletos no armário: como os historiadores se armam em Deus" (pp. 156-174) é ao mesmo tempo uma estimulante reflexão historiosófica e uma profissão de fé na humildade científica. "Factos" e "verdade" podem ser palavras muito pesadas. Darnton conta como descobriu, nos arquivos, as provas de que Marat estava inocente do roubo de que os seus detractores o acusam. E como as fontes documentais indiciam que o líder revolucionário (girondino) Brissot terá sido espião da polícia nos anos que antecederam a tomada da Bastilha. E ainda como uma ordenação diferente dos documentos permite conclusões factuais diferentes.

"O que estou eu a fazer? o mesmo que todo o historiador: a armar-me em Deus. Como explicou Santo Agostinho, Deus existe fora do tempo. Ele pode repetir a história como Lhe aprouver, para trás ou para a frente ou tudo isso ao mesmo tempo. Com certeza que o historiador cria vida. Ele sopra vida no barro que escava dos arquivos. Ele também julga os mortos." (p. 174).

Um pequeno grande livro, a pedir rápida tradução para tornar mais fácil o acesso a estudantes, professores e, em geral, a todos os curiosos da história das ideias. 


\section{NOTAS}

1. As traduções são da responsabilidade do autor da recensão.

\section{AUTORES}

\section{JOÃO PEDRO ROSA FERREIRA}

Centro de História da Cultura da UNL

Jornalista, Mestre em História Cultural e Política pela FCSH e investigador do CHC UNL. Professor convidado da European University. Publicou O jornalismo na emigração. Ideologia e política no «Correio Braziliense» (1807-1822); co-autor com Ferreira Fernandes de Frases que fizeram a História de Portugal (2006). Foi director da revista Focus. 